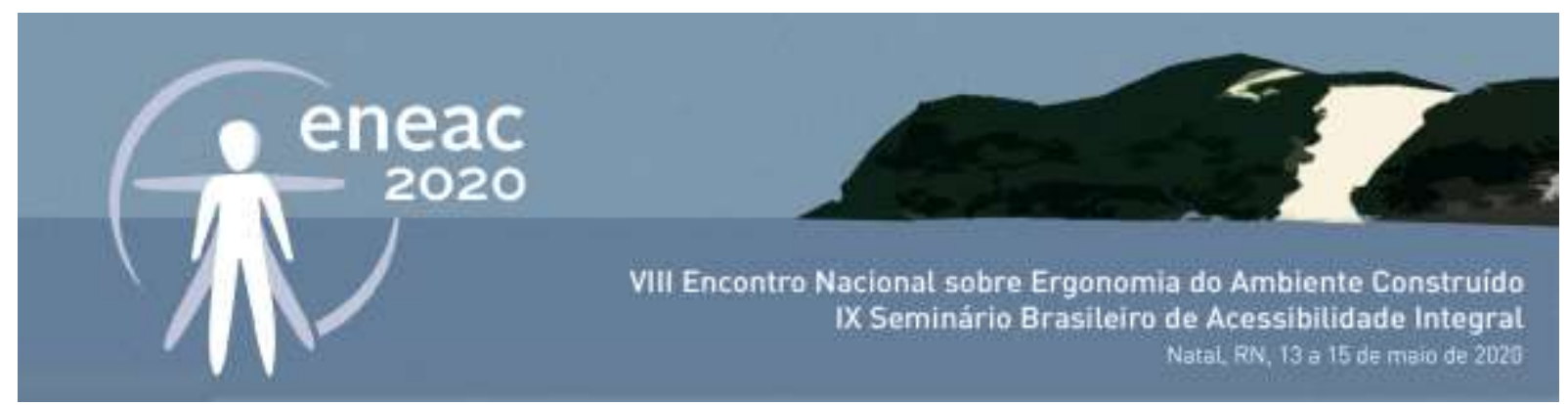

\title{
Tecnologias Assistivas como recurso facilitador da relação usuários idosos e suas moradias
}

\author{
Assistive Technologies as a resource to facilitate the relationship \\ between elderly users and their homes
}

ALINE EYNG SAVI

Dra., Universidade do Extremo Sul Catarinense, arquiteta.alinesavi@gmail.com

ELAINE GUGLIELMI PAVEI ANTUNES

Dra., Universidade do Extremo Sul Catarinense, elainegpa@unesc.net

NATHALIA BORSATTO D'AGOSTIN

Graduanda, Universidade do Extremo Sul Catarinense, nathaliadagostin@gmail.com

\section{RESUMO}

O envelhecimento humano passou a ser considerado um importante fenômeno social devido ao aumento da expectativa de vida da população. Nesse processo constata-se a maior probabilidade de experimentar incapacidades físicas e cognitivas, gerando crises de autonomia e identidade no idoso. A habitação por vezes torna-se um risco por não se adaptar às restrições inerentes ao envelhecimento, principalmente para a população idosa econômica e socialmente desfavorecida, a qual possui maior dificuldade de entendimento e acesso financeiro aos meios que facilitam a mobilidade dentro da moradia. Desenvolver ações de conscientização sobre a segurança domiciliar, focando em meios que respeitem os hábitos dos moradores e que garantam o sentimento de pertencimento, faz-se inerente. Nesse sentido, o Projeto de Iniciação Científica, iniciado em maio de 2019, objetiva: desenvolver manual arquitetônico para idosos que auxilie, através do uso de tecnologias assistivas, na autonomia para realização das atividades cotidianas. A metodologia utilizada trata-se de levantamento bibliográfico e pesquisa de campo. Os resultados são materiais ilustrativos para adaptação da moradia ao envelhecimento, ampliando o acesso aos direitos e serviços básicos para uma boa qualidade de vida. Nesse sentido, o manual de acessibilidade espacial faz-se importante ferramenta para esclarecer de maneira mais simples e informal a utilização desses recursos.

PALAVRAS-CHAVE: Tecnologia Assistiva, Acessibilidade Espacial, Moradia, Idoso, Manual

\section{ABSTRACT}

Human aging is now considered an important social phenomenon due to the increase in life expectancy of the population. In this process, the greater probability of experiencing physical and cognitive 


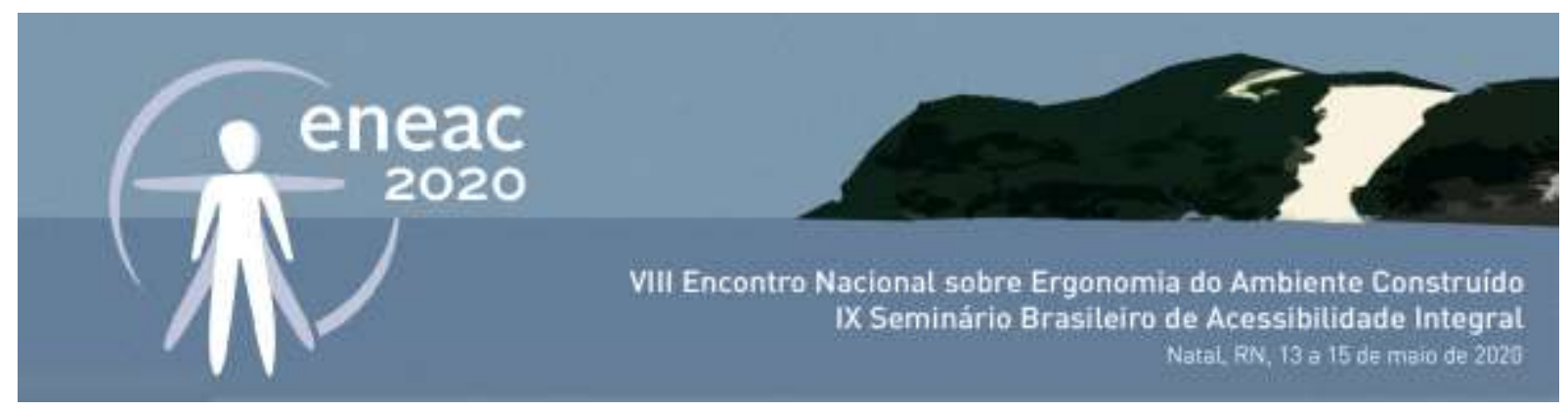

disabilities is observed, generating crises of autonomy and identity in the elderly. Housing sometimes becomes a risk for not adapting to the restrictions inherent in aging, especially for the economically and socially disadvantaged elderly population, which has greater difficulty in understanding and financial access to the means that facilitate mobility within the home. Developing awareness actions on home security, focusing on means that respect the habits of residents and ensure the sense of belonging, is inherent. In this sense, the Scientific Initiation Project, started in May 2019, aims to develop an architectural manual for the elderly that assists, through the use of assistive technologies, the autonomy to perform daily activities. The methodology used is bibliographic survey and field research. The results are illustrative materials for adapting housing to aging, expanding access to basic rights and services for a good quality of life. In this sense, the spatial accessibility manual is an important tool to clarify more simply and informally the use of these resources.

KEYWORDS: Assistive Technology, Spatial Accessibility, Housing, Elderly, Manual

\section{INTRODUÇÃO}

O termo Tecnologia Assistiva (TA) é utilizado para identificar recursos que fornecem auxílio e promovem a ampliação de uma habilidade funcional deficitária, contribuindo para a realização de determinada função que se encontra impedida devido a problemas funcionais ou pelo envelhecimento, gerando dessa forma, a acessibilidade dentro da moradia. Estão inclusos nesses recursos os materiais e produtos que favorecem a autonomia para a realização de tarefas cotidianas, proporcionando maior mobilidade e controle do ambiente. Exemplos desses equipamentos são os talheres modificados, suportes para utensílios domésticos, recursos para transferência e barras de apoio (BERSH, 2017).

O Comitê de Ajudas Técnicas (CAT) da Secretaria de Direitos Humanos da Presidência da República (2007) conceitua o termo tecnologia assistiva como:

[...] uma área do conhecimento, de característica interdisciplinar, que engloba produtos, recursos, metodologias, estratégias, práticas e serviços que objetivam promover a funcionalidade, relacionada à atividade e participação, de pessoas com deficiência, incapacidades ou mobilidade reduzida, visando sua autonomia, independência, qualidade de vida e inclusão social (CAT, Ata da Reunião VII, SDH/PR, 2007).

Em paralelo ao objetivo da utilização das tecnologias assistivas, a acessibilidade surge como outro termo fundamental. O decreto $\mathrm{n} 05.296$ de 2004, estabeleceu que a acessibilidade seria uma condição para utilização, com segurança e autonomia, total ou assistida, dos espaços, mobiliários, equipamentos urbanos, das edificações, dos serviços de transporte e dos dispositivos, sistemas e meios de comunicação e informação, por pessoa portadora de deficiência ou com mobilidade reduzida (BRASIL, 2004).

Ao garantir acessibilidade ao público idoso, cria-se a certeza de uma velhice saudável e com autonomia, uma vez que esses fatores dependem da forma como o idoso consegue interagir com os ambientes que frequenta. A preocupação com a relação idoso-ambiente é de suma importância, visto que o planejamento do ambiente construído é o que irá garantir qualidade de vida no processo de envelhecimento (JÚNIOR et al, 2013). O sentimento de satisfação para a pessoa idosa está em geral ligado a permanência no lar, local onde observa-se o envolvimento direto do indivíduo junto a um ambiente afetivo, o que constrói a sensação de conforto e segurança. Por esse fato, a permanência do idoso no próprio lar se faz fundamental, já que garante a manutenção de um estilo de vida 


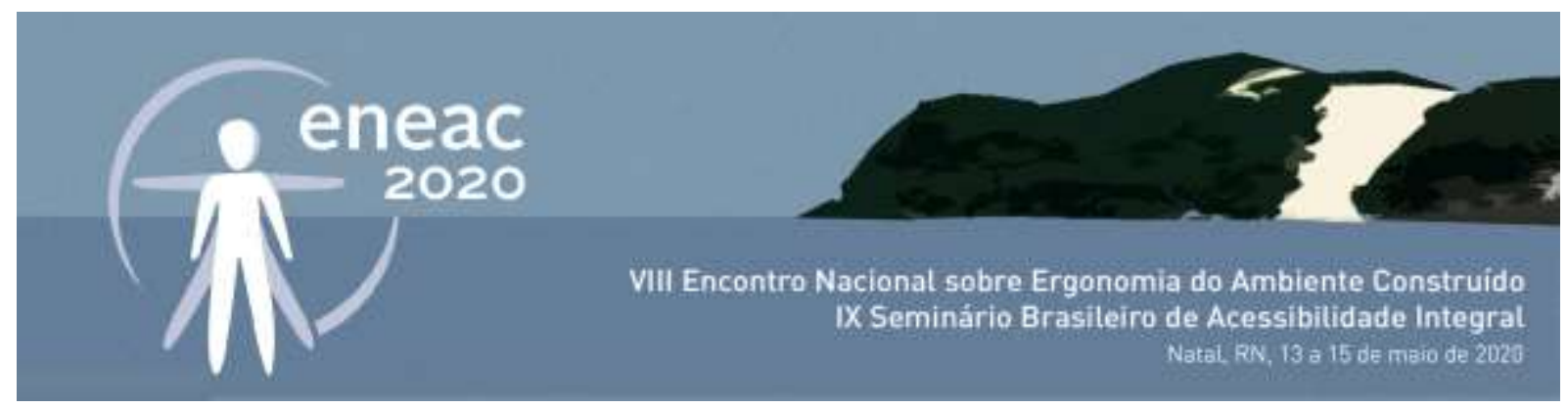

adequado, que promove a satisfação com a vida, a preservação da capacidade funcional e a autonomia (MINCATO; FREITAS, 2007).

É no lar o local onde cada indivíduo se sente importante, útil, único e desempenhando o seu papel e suas atividades básicas da vida diária de forma independente (LIMA; LIMA; RIBEIRO, 2010), por conta disso é importante adaptar a habitação às incapacidades físicas que surgem no decorrer do tempo. Promover acesso aos meios que geram acessibilidade dentro da moradia é garantir a sustentabilidade social e proporcionar o acesso aos direitos e serviços básicos para uma boa qualidade de vida da população idosa, tendo como foco principal a parcela econômica e socialmente desfavorecida, que possui maior dificuldade de entendimento e acesso financeiro a esses meios.

A qualidade de vida na velhice, segundo Torres (2015) pode ser caracterizada como:

\begin{abstract}
[...] um termo subjetivo, relacionado com a maneira como o indivíduo interpreta a sua realidade imediata, o que acontece em função de seus valores, princípios e interesses. [...] Por qualidade de vida percebida entende-se a maneira como cada pessoa avalia qualquer domínio de suas competências comportamentais. Ao bem-estar subjetivo corresponde a autoavaliação dos estados afetivo (quer positivos quer negativos) relacionados à vida, o que envolve indicadores cognitivos e emocionais (TORRES, 2015, p. 53-55).
\end{abstract}

Assim, pode-se compreender que a qualidade de vida envolve a necessidade do indivíduo conhecer a dinâmica das interações que estabelece com o ambiente, visto que as condições ambientais expressam relação direta com o bem-estar na velhice. Dessa forma, é necessário que o local seja compatível com as capacidades físicas e competências comportamentais de cada idoso, permitindo que os mesmos possam atuar para que seu ambiente se torne mais seguro e que seu cotidiano seja mais agradável e adequado as necessidades que possuem (TORRES, 2015).

O fenótipo de um envelhecimento fragilizado reúne elementos como a perda de peso, a fadiga, a redução da velocidade da marcha e a diminuição das atividades físicas (RIBEIRO et al, 2016). Esses componentes, quando não acompanhados desde o início do processo de envelhecimento através de adaptações às novas dificuldades e programas que promovam a recuperação da saúde do idoso, abrem espaço para que as incapacidades progressivas nas atividades diárias se acumulem. Esse processo como um todo acaba retirando a autonomia do idoso e distancia o país do envelhecimento bem-sucedido (ANDRADE; PEREIRA, 2009). Preocupar-se com as alterações dessa etapa da vida é essencial para que as limitações do corpo não resultem em problemas para interação com o ambiente construído.

Pode-se avaliar que os elementos expostos remetem a questionamentos acerca da qualidade de vida dos idosos, bem como ao processo de adaptação da moradia às novas necessidades que aparecem com o tempo, e é por esse fato que estudar o envelhecimento é fundamental. Assim pode-se compreender os processos degenerativos que lhe estão associados e, posteriormente, desenvolver estratégias que atenuem os efeitos negativos dessa etapa da vida, de forma a garantir acessibilidade, inserção social e, sobretudo, autonomia. Há a necessidade de estudo sobre a adaptação espaçofuncional das moradias desse grupo para que se abra espaço à procura de meios que promovam maior acessibilidade a esse tema e possam, paralelamente, gerar sustentabilidade social ao se aproximar da leitura leiga e criar recursos funcionais para que a parcela de idosos com dificuldade de acesso a esses materiais possa ser atendida.

Torna-se relevante, portanto, realizar um estudo que investigue as principais queixas com relação a vivência de idosos dentro de sua própria habitação, identificando os problemas de mobilidade, e, 


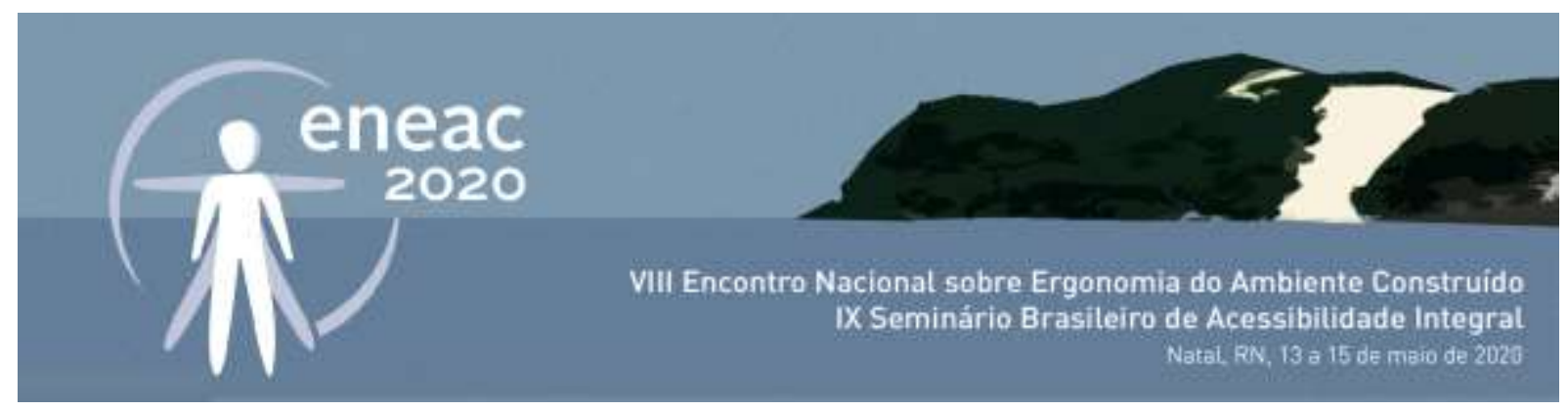

posteriormente, criando propostas de soluções a partir de tecnologias assistivas mais acessíveis ao público leigo, especialmente os idosos com problemas de comunicação e compreensão. Dessa forma, a pesquisa consiste em Projeto de Iniciação Científica que se utilizará da criação de um manual arquitetônico para auxiliar na autonomia para realização das atividades básicas e cotidianas dos idosos, minimizando as adversidades evidenciadas pelo público investigado.

O produto final trata da confecção de materiais ilustrativos para adaptação da moradia ao envelhecimento, considerando a aplicação do conteúdo existente em normas técnicas para a apresentação mais simplificada, através de ilustrações simples. O seguinte artigo abordará, portanto, os conceitos e metodologias estudados e empregados na pesquisa, segundo os quais foi possível obter as informações necessárias para a posterior criação do manual arquitetônico.

\section{TECNOLOGIA ASSISTIVA APLICADA À MORADIA}

As pessoas analisam continuamente todas as situações e contextos em que estão vinculadas, sendo que essas condições também se mantem com relação aos ambientes que cada indivíduo frequenta ou, no caso da moradia, realiza atividades cotidianas, as quais permitem que considerações a respeito do conforto, facilidade de locomoção, dimensões adequadas e segurança, sejam estabelecidas como favoráveis ou não (ELALI, 2010).

Segundo Torres (2015), a moradia possui características que a diferem de outros locais devido as atividades ali realizadas, ao tempo despendido no local e pelas relações afetivas estabelecidas nela, fatores que acabam por gerar apego ao lugar. Percebe-se que, na velhice, manifesta-se o desejo de permanecer no ambiente residencial ao invés de recorrer as instituições, o que demonstra que a moradia está vinculada a autonomia e a auto segurança. A casa, portanto, seria o local repleto de significados e experiências primordiais ao indivíduo idoso, visto que ela guarda diversos atributos construídos ao longo da vida, aos quais são agregados valores afetivos. Dessa forma, a moradia é percebida como um dos pontos social e emocionalmente centrais no processo de envelhecimento, tornando-se fonte de identidade para o idoso.

Algumas mudanças que surgem na fase do envelhecimento exigem atenção, pois afetam os campos biológicos, psíquico e social, aumentando a probabilidade de experimentar graves incapacidades físicas e cognitivas. $\mathrm{O}$ aparecimento da solidão, a perda dos papéis sociais, os prejuízos psicológicos, motores e afetivos também se destacam nesse processo (ARAÚJO, 2007). Devido a esses fatores, torna-se importante para o indivíduo idoso permanecer em sua própria residência, pois configura a manutenção da sua zona de conforto e estreita a ligação com sua história, consolidando a felicidade pessoal na idade madura. Por outro lado, essa permanência é marcada por empecilhos ao realizar atividades cotidianas, fazendo com que muitos se vejam obrigados a deixar seus lares, os espaços conhecidos e amigos, porque suas residências, de concepção antiga, não possuem as características para que se possa garantir uma vivência segura, adaptada as novas necessidades (BARROS, 2000).

Aplicar, conforme a necessidade de cada caso, parâmetros de arquitetura com base nas tecnologias assistivas são essenciais para oferecer condições plenas de segurança e conforto, melhorando a qualidade de vida. Afinal, o espaço físico habitado pode incentivar, deprimir, cuidar ou colocar em risco o ser humano que o utiliza. A utilização das tecnologias assistivas consolidaria a realidade de promover uma casa segurança, diminuindo a necessidade de cuidadores, prevenindo acidentes, quedas e institucionalizações, bem como resgataria a autonomia e independência do idoso, fazendo 


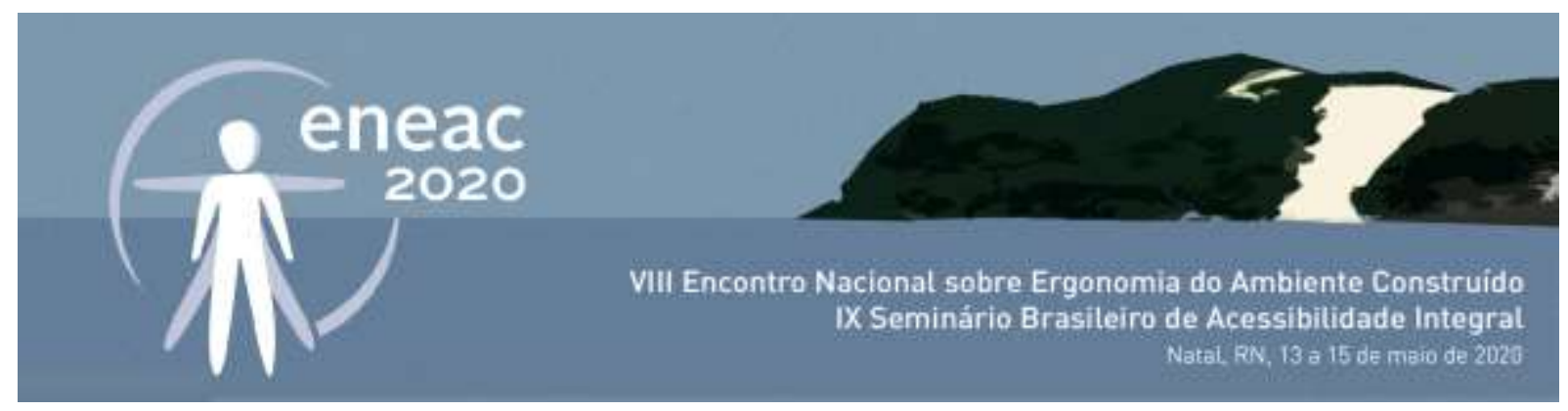

com que ele não sinta mais a necessidade de se ajustar à falta de acessibilidade dentro da própria casa.

\section{ESTUDO DE CASO E METODOLOGIA}

O desenvolvimento da sustentabilidade social está estritamente ligado à valores culturais, éticos e à atitudes e comportamentos humanos, incluindo a qualidade de vida dos indivíduos. O conceito de sustentabilidade social lida com os padrões de vida em diferentes contextos culturais e sociais, tratando também sobre a adequação dos locais onde as relações sociais se desenvolvem, relacionando esse fato à indicadores como acessibilidade, qualidade estética arquitetônica, flexibilidade da edificação, mobilidade, experiência habitacional e ambiente interno (SILVA, 2007).

Nesse sentido, o projeto de iniciação científica, que tem como objetivo desenvolver recursos de tecnologia assitiva que contribuam para a acessibilidade dentro da moradia, está diretamente relacionado à sustentabilidade social, visto que prevê a adequação dos ambientes das residências do público idoso para que os empecilhos enfrentados pelos mesmos, na realização de atividades cotidianas, possam ser vencidos com mais facilidade, propiciando, dessa forma, autonomia e qualidade de vida no processo de envelhecimento.

O público alvo são idosos que residem na parcela urbana da cidade de Criciúma/SC. A área - 8,36\% do território municipal - se desenvolve numa extensão contínua na mancha urbana a sudeste. Estão incluídos grande vazios que em sua maioria são depósitos de rejeito de carvão. Tais espaços são o resultado da exploração à céu aberto no momento da expansão da mineração, refletindo negativamente no ambiente. Nesse recorte está o menor Índice de Desenvolvimento Humano (IDH) e o pela razoes supracitadas foi selecionado para estudo.

Para alcançar o objetivo geral de desenvolver, por meio de manual arquitetônico para idosos (e com o uso de recursos de tecnologia assistiva), que auxiliando na autonomia para realização das atividades cotidianas, o projeto de iniciação cientifica tem por metodologia o levantamento bibliográfico (MARCONI; LAKATOS, 2010) e a pesquisa de campo (GIL, 2017) que tem como objetivo analisar as características e adversidades de mobilidade na habitação de determinada população de idosos, por meio da utilização de técnicas padronizadas de coleta de dados, como o questionário. 0 sistema aplicado foi o levantamento, no qual coletou-se informações com relação ao problema em estudo, sendo que a interpretação de tais dados se deu pelo método de análise quantitativo (GIL, 2017).

Para tanto, foi aplicado um formulário de avaliação (Quadro 1) que pudesse apontar a situação de moradia e dependência dos idosos, bem como apresentar as atividades que realizam e os empecilhos que existem ao praticá-las. O objetivo foi avaliar como esses fatores estão influenciando na qualidade de vida dos idosos e apontar os principais problemas encontrados pelos mesmos com relação a acessibilidade espacial e deslocamentos dentro da habitação, especialmente dentro dos banheiros e dormitórios, visando numa etapa posterior propor uma cartilha de apoio aos idosos para adaptação espaço-funcional de suas moradias.

Quadro 1: Formulário de Avaliação

Quadro de moradia - Banheiro

1. Seu banheiro possui barra de apoio? ( ) Sim ( ) Não Se sim, qual o tipo de barra e onde ela se encontra? 


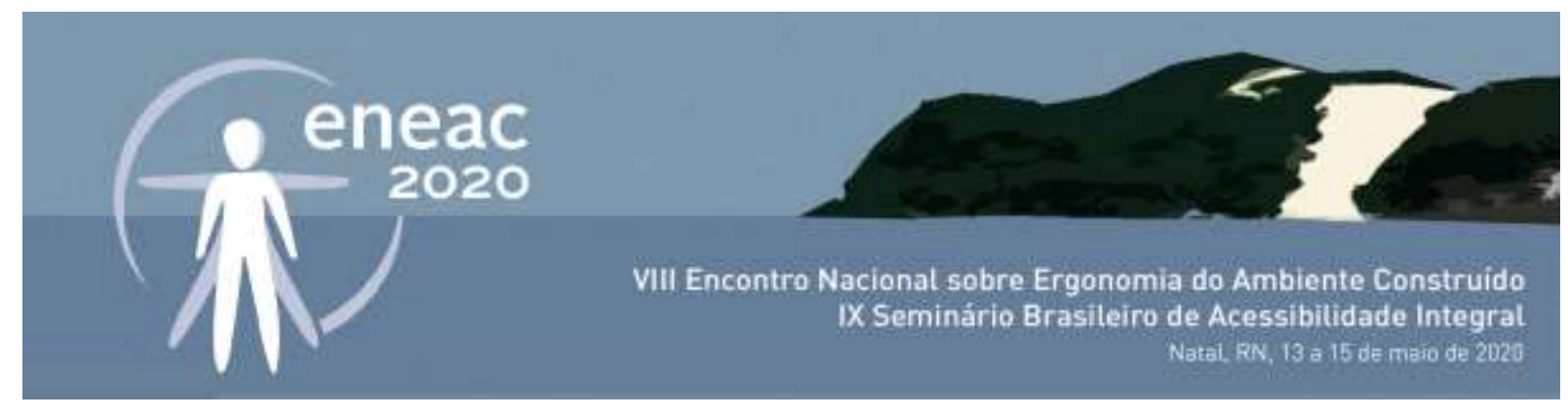

2. Seu banheiro possui tapete? ( ) Sim ( ) Não Se sim, qual o tipo de tapete e onde ele se encontra?

3. Você considera que a bacia sanitária do seu banheiro possui uma altura adequada? ( ) Sim

( ) Não (Acho muito alta / muito baixa)

4. Você considera o piso do seu banheiro escorregadio? ( ) Sim ( ) Não

5. A quina da bancada da pia presente no seu banheiro é arredondada? ( ) Sim ( ) Não

6. A maçaneta da torneira da pia e do chuveiro são esféricas / arredondadas? ( ) Sim ( ) Não

7. Você considera que o boxe do seu banheiro possui uma dimensão adequada? ( ) Sim ( ) Não (Acho pequeno / estreito)

8. O boxe possui algum tipo de banco que permite que você tome banho sentado? ( ) Sim ( ) Não

9. Você já tropeçou no desnível existente no boxe do banheiro? ( ) Sim ( ) Não

10. Você acredita que esse desnível pode ser fator de risco para uma possível queda no banheiro? ( ) Sim ( ) Não

11. A porta do boxe é de qual material? ( ) Vidro （） Possui uma cortina （） Não possui qualquer tipo de divisão ( ) Plástico ( ) Acrílico

12. Você considera que o seu banheiro é bem iluminado?（） Sim （） Não (Sinto dificuldade de enxergar coisas sobre a bancada da pia ou dentro do boxe)

13. Você considera que a pia, a bacia sanitária e o boxe do seu banheiro estão organizados em locais adequados que permitem a livre circulação pelo ambiente? ( ) Sim （） Não (Sinto dificuldade de me movimentar dentro do banheiro / Acho o banheiro muito pequeno)

14. Você já caiu no banheiro? ( ) Sim （） Não Se sim, qual foi o motivo da queda?

Quadro de moradia - Dormitório:

1. Seu quarto está localizado no pavimento térreo da sua residência? ( ) Sim （） Não Se não, o acesso ao pavimento onde ele está localizado é feito por uma escada ou rampa?

2. O seu quarto está localizado próximo ao banheiro? ( ) Sim ( ) Não

3. Você considera que o seu quarto é bem iluminado? ( ) Sim ( ) Não (Sinto dificuldade em enxergar coisas sobre as prateleiras e dentro do armário)

4. O seu quarto possui barra de apoio? ( ) Sim （ ) Não Se sim, qual o tipo de barra e onde ela se encontra?

5. O seu quarto possui tapete? ( ) Sim ( ) Não Se sim, qual o tipo de tapete e onde ele se encontra?

6. Você considera que a porta de entrada para o seu quarto possui uma largura adequada? ( ) Sim ( ) Não (Acho muito estreita)

7. Você sente dificuldade para abrir a janela do seu quarto? ( ) Sim (É uma janela pesada e difícil de levantar / empurrar) ( ) Não

8. A maçaneta da porta de entrada para o quarto é esférica / arredondada? ( ) Sim ( ) Não

9. Os puxadores das gavetas de armários e cômodas são esféricos / arredondados? ( ) Sim ( ) Não

10. Você encontra alguma dificuldade para alcançar roupas ou outros objetos que se encontram no seu armário? ( ) Sim (Alguns objetos se encontram em prateleiras muito altas) ( ) Não

11. Os armários, cômodas, mesas de canto ou estantes, presentes no seu quarto, estão fixados à parede ou ao chão? ( ) Sim ( ) Não

12. As quinas dos móveis presentes no seu quarto são arredondadas?（） Sim （） Não

13. A altura da sua cama permite que você consiga alcançar os pés no chão quando está sentado(a)? ( ) Sim ( ) Não

14. Ao lado da sua cama existe algum ponto de luz (abajur ou arandela) ou algum interruptor que possa acionar um ponto de luz? ( ) Sim ( ) Não

15. Você considera que os móveis do seu quarto estão organizados em locais adequados que permitem a livre circulação pelo ambiente? ( ) Sim （）Não (Sinto dificuldade de me movimentar pelo quarto / Acho o quarto muito pequeno)

16. Você já caiu no quarto? ( ) Sim （ ) Não Se sim, qual foi o motivo da queda? 


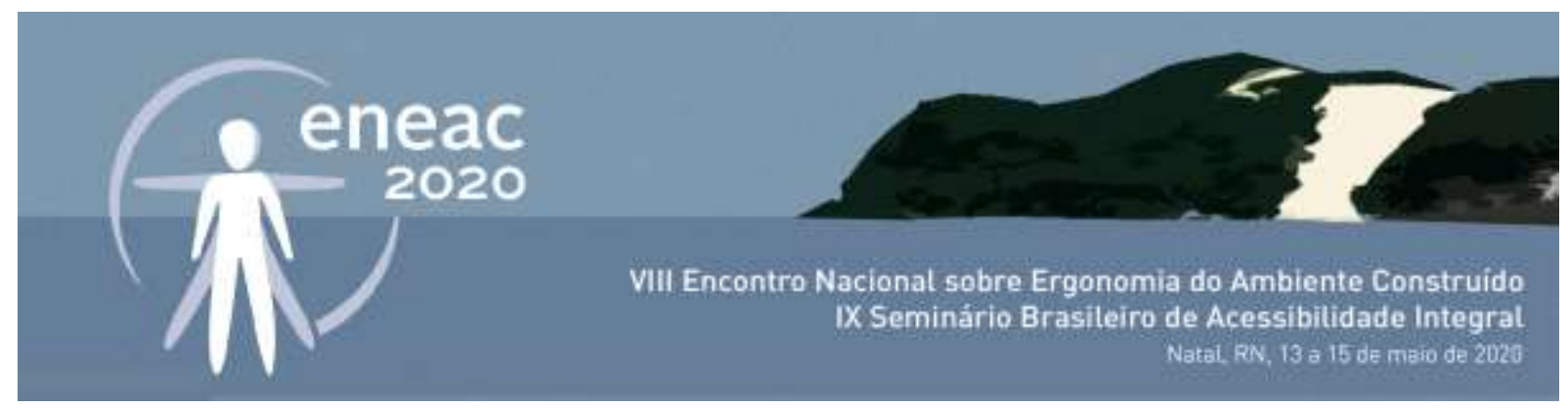

O formulário de avaliação foi dividido em dois domínios: "Quadro de moradia - Banheiro" e "Quadro de moradia - Dormitório" e aplicado aos idosos que concordaram em participar da pesquisa. As informações coletadas foram digitadas em um banco de dados no programa da Microsoft Office Excel versão 2013, onde os resultados foram analisados. A participação do público investigado foi levada em conta ao elaborar o formulário, propondo perguntas acerca de melhorias que poderiam ser feitas no espaço, a fim de posteriormente atender as necessidades expostas da melhor forma.

Para ampliar a coleta de dados no estudo de caso, acrescentou-se a metodologia do Grupo Focal, baseada nos estudos de Martin W. Bauer e George Gaskell (1996), o qual se caracteriza por ser um grupo de discussão informal e de tamanho reduzido, que tem o propósito de obter informações de caráter qualitativo em profundidade, onde os participantes discutem sobre um tema específico prédeterminado por um moderador. As informações e discussões surgem a partir da interação entre os participantes (MORGAN, 1996).

O objetivo de propor o Grupo Focal é criar um ambiente favorável à interação, permitindo que as pessoas possam explicar como consideram uma experiência, uma ideia ou um evento (nessa pesquisa: a questão da acessibilidade dos idosos em suas residências), visto que a discussão em grupo colabora para fornecer informações sobre o que as pessoas pensam, sentem e de que forma agem a respeito de determinado assunto, gerando pluralidade de ideias (VERGARA, 2004). A importância de realizar essa técnica está na obtenção de resultados inesperados que surgem a partir da discussão livre e da confiança na interação dos membros do grupo (OLIVEIRA; FILHO; RODRIGUES, 2007), visto que esse recurso propicia um ambiente mais natural e com informações mais autênticas para a entrevista, permitindo assim que seja vencida a dificuldade de verbalização e de exporto as ideias que o questionário trouxe.

Para auxiliar nos resultados, a pesquisa utilizou imagens, que ilustram diferentes ambientes, móveis e tecnologias asssitivas dentro de residências. Esse material foi selecionado para ser utilizado durante a realização do Grupo Focal, servindo como auxílio para estimular as conversas, bem como para exemplificar com maior clareza os temas abordados, garantindo dessa forma o foco no assunto das discussões.

\section{RESULTADOS ENCONTRADOS}

A amostra obtida foi de 28 idosos, dos quais 21 participam do grupo de idosos dos Bairro Mineira Velha e Mina União e 7 fazem parte do Centro Especializado em Recuperação (CER), que acontece na Universidade do Extremo Sul Catarinense - UNESC. Os dados coletados a partir da aplicação do questionário e da técnica do grupo focal foram organizados no seguinte quadro (Quadro 2).

Quadro 2: Dados da amostra obtida

\begin{tabular}{lrr}
\hline \multicolumn{1}{c}{ Variável } & Frequência \\
\cline { 2 - 3 } & Número de idosos & Porcentagem geral \\
\hline Presença de barra de apoio no banheiro & 5 & $17,85 \%$ \\
\hline Sim & 23 & $82,15 \%$ \\
\hline Não & & \\
\hline Local onde a barra se encontra instalada & $40 \%$ (considerando os 5 idosos que \\
\hline pentro do boxe & 2 & possuem barra de apoio)
\end{tabular}




\section{$\mathbb{N}^{\text {eneac }}$}

VIII Encontro Nacional sobre Ergonomia do Ambiente Construido

IX Seminário Brasileiro de Acessibilidade Integral

Natai RN, 13 a 15 de mario de 2020

\begin{tabular}{|c|c|c|}
\hline Na frente da bacia sanitária & 2 & $\begin{array}{l}40 \% \text { (considerando os } 5 \text { idosos que } \\
\text { possuem barra de apoio) }\end{array}$ \\
\hline Sem relato & 1 & $\begin{array}{l}20 \% \text { (considerando os } 5 \text { idosos que } \\
\text { possuem barra de apoio) }\end{array}$ \\
\hline \multicolumn{3}{|l|}{ Presença de tapete no banheiro } \\
\hline Sim & 20 & $71,42 \%$ \\
\hline Não & 8 & $28,58 \%$ \\
\hline \multicolumn{3}{|c|}{ Considera o piso do banheiro escorregadio } \\
\hline Sim & 15 & $53,57 \%$ \\
\hline Não & 12 & $42,85 \%$ \\
\hline Sem relato & 1 & $3,57 \%$ \\
\hline \multicolumn{3}{|c|}{ Considera o boxe com dimensão adequada } \\
\hline Sim & 20 & $71,42 \%$ \\
\hline Não & 5 & $17,85 \%$ \\
\hline Sem relato & 3 & $10,71 \%$ \\
\hline \multicolumn{3}{|l|}{ Presença de banco no boxe } \\
\hline Sim & 3 & $10,71 \%$ \\
\hline Não & 22 & $78,57 \%$ \\
\hline Sem relato & 3 & $10,71 \%$ \\
\hline \multicolumn{3}{|c|}{ Tropeço por conta do desnível existente no boxe } \\
\hline Sim & 4 & $14,28 \%$ \\
\hline Não & 18 & $34,28 \%$ \\
\hline Sem relato & 6 & $21,42 \%$ \\
\hline \multicolumn{3}{|c|}{$\begin{array}{l}\text { Considera que esse desnível possa ser fator de risco } \\
\text { para possível queda }\end{array}$} \\
\hline Sim & 10 & $35,71 \%$ \\
\hline Não & 14 & $50 \%$ \\
\hline Sem relato & 4 & $14,28 \%$ \\
\hline \multicolumn{3}{|c|}{ Considera o banheiro bem iluminado } \\
\hline Sim & 25 & $89,28 \%$ \\
\hline Não & 1 & $3,57 \%$ \\
\hline Sem relato & 2 & $7,14 \%$ \\
\hline \multicolumn{3}{|c|}{$\begin{array}{l}\text { Considera que o banheiro possui layout que permite a } \\
\text { livre circulação }\end{array}$} \\
\hline Sim & 24 & $85,71 \%$ \\
\hline Não & 1 & $3,57 \%$ \\
\hline Sem relato & 3 & $10,71 \%$ \\
\hline \multicolumn{3}{|l|}{ Queda no banheiro } \\
\hline Sim & 2 & $7,14 \%$ \\
\hline Não & 24 & $85,71 \%$ \\
\hline Sem relato & 2 & $7,14 \%$ \\
\hline \multicolumn{3}{|l|}{ Motivo da queda } \\
\hline Deslize da cadeira de rodas & 1 & $\begin{array}{l}50 \% \text { (considerando os } 2 \text { idosos que } \\
\text { relataram queda) }\end{array}$ \\
\hline Sem relato & 1 & $\begin{array}{l}50 \% \text { (considerando os } 2 \text { idosos que } \\
\text { relataram queda) }\end{array}$ \\
\hline \multicolumn{3}{|c|}{ Considera o dormitório bem iluminado } \\
\hline Sim & 25 & $89,28 \%$ \\
\hline Não & 1 & $3,57 \%$ \\
\hline Sem relato & 2 & $7,14 \%$ \\
\hline \multicolumn{3}{|c|}{ Presença de barra de apoio no dormitório } \\
\hline Sim & 1 & $3,57 \%$ \\
\hline Não & 25 & $89,28 \%$ \\
\hline
\end{tabular}




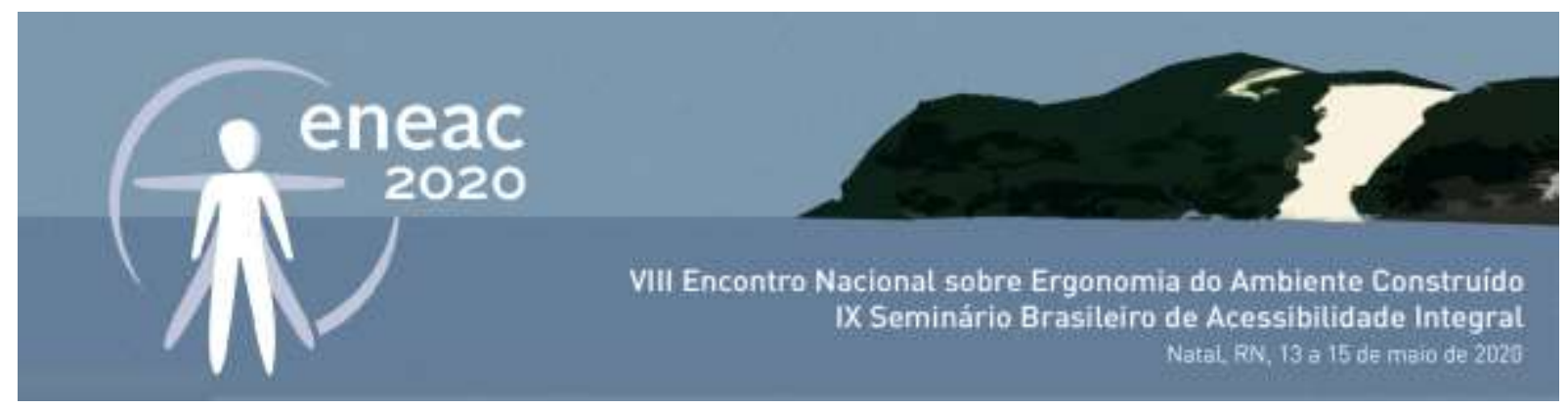

\begin{tabular}{|c|c|c|}
\hline Sem relato & 2 & $7,14 \%$ \\
\hline \multicolumn{3}{|c|}{ Presença de tapete no dormitório } \\
\hline Sim & 12 & $42,85 \%$ \\
\hline Não & 14 & $50 \%$ \\
\hline Sem relato & 2 & $7,14 \%$ \\
\hline \multicolumn{3}{|c|}{$\begin{array}{l}\text { Encontra dificuldade para alcançar roupas e/ou } \\
\text { objetos que se encontram na parte superior de } \\
\text { armários ou prateleiras }\end{array}$} \\
\hline Sim & 12 & $42,85 \%$ \\
\hline Não & 16 & $57,14 \%$ \\
\hline \multicolumn{3}{|c|}{ Quinas dos móveis arredondadas } \\
\hline Sim & 9 & $32,14 \%$ \\
\hline Não & 18 & $64,28 \%$ \\
\hline Sem relato & 1 & $3,57 \%$ \\
\hline \multicolumn{3}{|c|}{$\begin{array}{l}\text { Presença de ponto de luz ou interruptor ao lado da } \\
\text { cama }\end{array}$} \\
\hline Sim & 14 & $50 \%$ \\
\hline Não & 14 & $50 \%$ \\
\hline \multicolumn{3}{|c|}{$\begin{array}{l}\text { Considera que o dormitório possui layout que permite } \\
\text { a livre circulação }\end{array}$} \\
\hline $\operatorname{Sim}$ & 25 & $89,28 \%$ \\
\hline Não & 3 & $10,71 \%$ \\
\hline \multicolumn{3}{|l|}{ Queda no dormitório } \\
\hline Sim & 6 & $21,42 \%$ \\
\hline Não & 22 & $78,57 \%$ \\
\hline \multicolumn{3}{|l|}{ Motivo da queda } \\
\hline Tropeço por conta do tapete & 2 & $\begin{array}{l}33,33 \% \text { (considerando os } 6 \text { idosos que } \\
\text { relataram queda) }\end{array}$ \\
\hline Ao sair da cama & 2 & $\begin{array}{l}33,33 \% \text { (considerando os } 6 \text { idosos que } \\
\text { relataram queda) }\end{array}$ \\
\hline Problemas motores & 2 & $\begin{array}{l}33,33 \% \text { (considerando os } 6 \text { idosos que } \\
\text { relataram queda) }\end{array}$ \\
\hline
\end{tabular}

Os dados expostos revelam que $53 \%$ dos idosos considera escorregadio o piso do banheiro da sua moradia, além disso, $35 \%$ considera que o desnível existente no boxe é fator de risco para possíveis quedas, sendo que $7 \%$ relataram a ocorrência de queda. Esse último levantamento está relacionado ao fato de que $82 \%$ dos entrevistados não possui barra de apoio no banheiro, bem como $71 \%$ possui tapete nesse ambiente. Já com relação ao dormitório o questionário pôde apresentar que $42 \%$ dos idosos possui dificuldade de alcançar objetos em prateleiras mais elevadas, $89 \%$ não possui barra de apoio e $42 \%$ possuiu tapete nesse ambiente, fatos que corroboram para o dado de que $21 \%$ dessa amostra relatou ocorrência de queda no local.

Durante a realização da técnica do Grupo Focal, grande parte dos idosos relatou ter consciência da necessidade de adaptação do banheiro e do dormitório, visto as dificuldades que enfrentam durante a realização de atividades cotidianas. As barras de apoio foram caracterizadas pelos idosos como elementos fundamentais para a prevenção de quedas, e embora grande parte não as possua, relataram que sentem a necessidade de instalação. Já com relação aos tapetes, foram caracterizados, em grande parte, como puramente decorativos no ambiente. Ainda segundo os entrevistados, a dificuldade de alcançar objetos em prateleiras mais elevadas fez com que, muitas vezes, os mesmos utilizassem cadeiras, escadas ou até mesmo as elevações do próprio armário para apanhar 


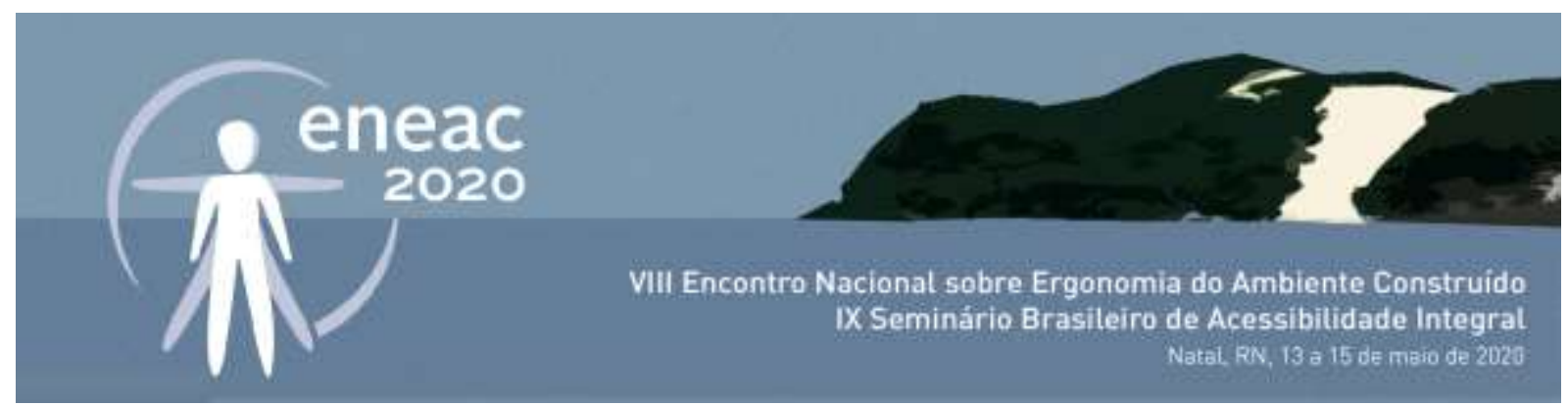

determinados objetos ou roupas, o que demonstra o risco ao qual estão expostos diariamente. A respeito disso, considera-se clara a necessidade de desenvolver ações de conscientização sobre a segurança domiciliar, focando em meios que respeitem os hábitos e costumes dos moradores. Segundo Barros (2000), é extremamente importante para o indivíduo idoso permanecer em sua própria residência, pois configura a manutenção da sua zona de conforto e estreita a ligação com sua história, consolidando a felicidade pessoal na idade madura.

Por outro lado, essa permanência acaba sendo marcada por empecilhos como subir uma escada, tomar banho sozinho, preparar a própria comida e arrumar a casa, fazendo com que muitos se vejam obrigados a deixar seus lares, os espaços conhecidos e amigos, porque suas residências, de concepção antiga, não possuem as características para que se possa garantir uma vivência segura, adaptada as novas necessidades (BARROS, 2000).

Aplicar, conforme a necessidade de cada caso, parâmetros de arquitetura com base nas tecnologias assistivas são essenciais para oferecer condições plenas de segurança, melhorando a qualidade de vida. Afinal, o espaço físico habitado pode incentivar, cuidar ou colocar em risco o ser humano que o utiliza. Assim, ainda segundo Barros (2000, p.17):

[...] à medida que diminui a capacidade individual das pessoas num processo gradual que acaba por
ajustar o indivíduo às inconveniências, a pessoa acaba assumindo que ela é o problema, numa inversão
dos valores. Na verdade, o espaço por vezes, é que tem problemas, não serve mais às suas necessidades.

Os primeiros resultados têm demonstrado que os idosos classificam os banheiros como maior necessidade de adaptação, e que apesar do conhecimento de algumas tecnologias assistivas que minimizariam riscos de acidentes, tem dificuldade de entendimento e de acesso financeiro a elas. Nesse sentido, o manual faz-se importante ferramenta para esclarecer de maneira mais simples e informal a utilização desses recursos. O manual (Figura 1) está sendo organizado através de ilustrações simples, construídas a partir da memória oral dos idosos acerca dos ambientes de suas próprias casas. Após, o manual recebe apontamentos técnicos, contudo em linguagem acessível e breve, permitindo o entendimento de um maior grupo de idosos. Registra-se que cada uma dessas etapas possui validação pelos idosos que participaram do questionário.

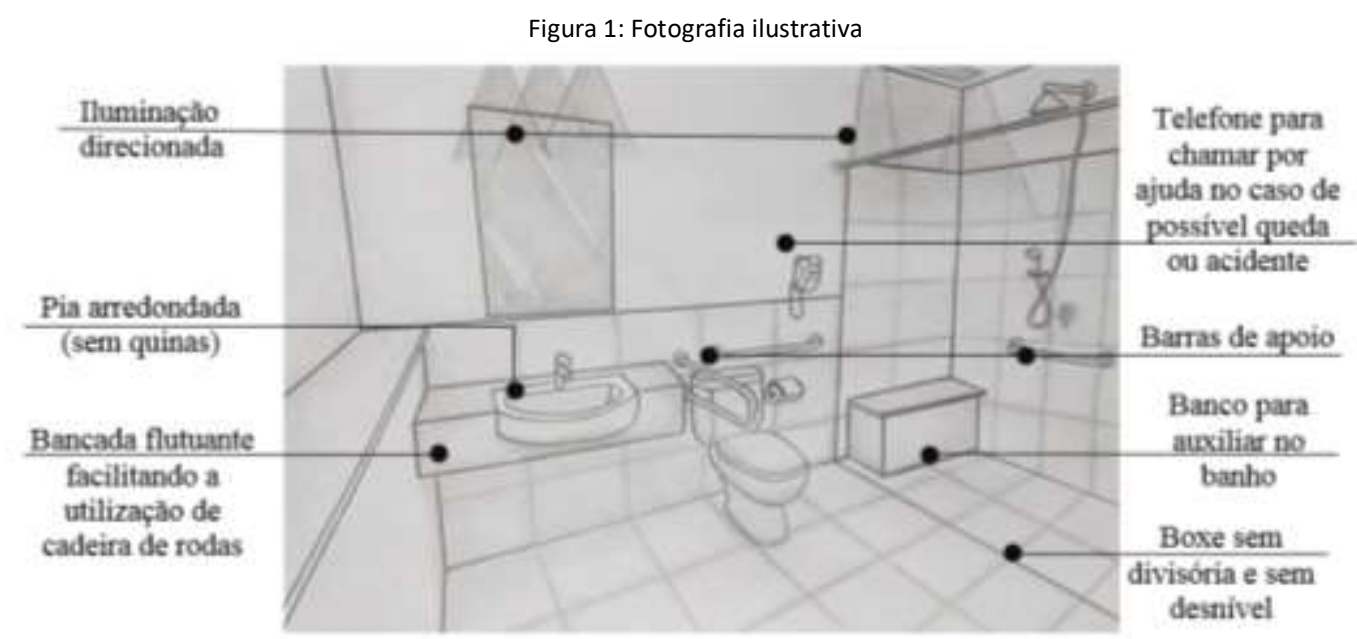




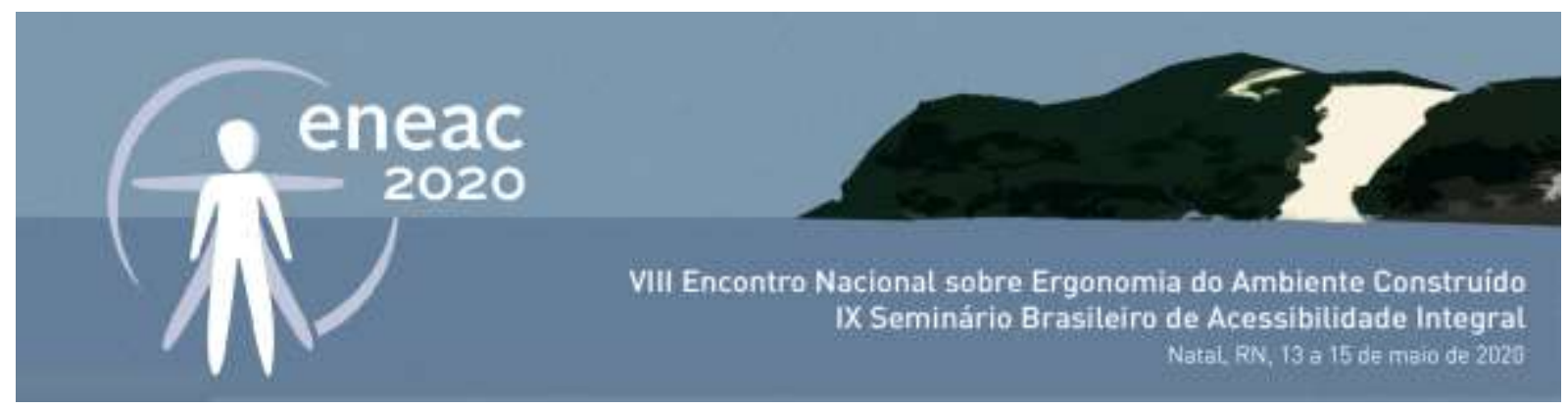

Fonte: Autores, 2019.

\section{CONSIDERAÇÕES FINAIS}

O crescente número de idosos brasileiros é um alerta para diversos segmentos da sociedade que lidam com acessibilidade, mobilidade e adaptação. A adaptação da residência dos idosos se apresenta como elemento importante na manutenção da autonomia e independência, por esse motivo é necessário que essa fase da vida envolva planejamento, de forma que as adequações venham ao encontro das necessidades de cada caso, prevenindo e amenizando os riscos referentes aos problemas físicos, emocionais e funcionais.

A "casa segura", portanto, seria aquela que contenha características de habitabilidade e de funcionalidade que criem segurança no vivenciar o lar. É importante também que ela seja visualizada como uma casa normal, de modelo simples e funcional, para que não se aplique um caráter excepcional estigmatizado (e.g. "a casa do velhinho"), afastando da sociedade uma parcela de pessoas as quais, na verdade, pretende-se oferecer maior integração e autonomia.

Ao dar voz aos idosos, usuários diretamente envolvidos na manutenção e ocupação das moradias, é possível perceber as dificuldades que eles enfrentam ao realizar atividades cotidianas e quais as características da moradia que não permitem que o local se adapte as necessidades que 0 envelhecimento apresenta. Essa avaliação seria, portanto, uma maneira de conscientizar projetistas e executores com relação à responsabilidade social que possuem no exercício de sua profissão, mostrando a importância de planejar a casa à medida que seus ocupantes vão envelhecendo (ELALI, 2010).

A construção de um manual de acessibilidade que apresente de forma mais simples a tecnologia assistiva que já é de conhecimento técnico, permitirá que os próprios idosos reconheçam suas limitações e tenham autonomia (a maior parte deles) para tomar decisões quanto à adaptação de suas moradias, corroborando para a construção de um conceito holístico de projeto inclusivo, no qual o usuário é parte investigado e parte decisória. Criar meios de adaptação da moradia é permitir que esse local, ponto social e emocionalmente central no processo de envelhecimento, continue sendo a fonte de identidade para o idoso.

\section{AGRADECIMENTOS}

Fonte financiadora - Edital 049/2019 - Programa PIC Artigo 170/SC e Grupo de Pesquisa em Desempenho de Estruturas e Construção Civil.

\section{REFERÊNCIAS}

ANDRADE, Valéria Sousa; PEREIRA Leani. Influência da tecnologia assistiva no desempenho funcional e na qualidade de vida de idosos comunitários frágeis: uma revisão bibliográfica. Revista Brasileira de Geriatria e Gerontologia. 2009, vol. 12 , n. 1, p. 113-122.

ARAÚJO, Fátima. Validação do Índice de Barthel numa amostra de idosos não institucionalizados. Revista Portuguesa de saúde pública. 2007 , vol. 25, n. 2, p. 59-66.

BARROS, Cybele Ferreira Monteiro de. Casa segura: Uma arquitetura para a maturidade. Rio de Janeiro: Pod Editora, 2000. 96 p. il.

BERCH, Rita. Introdução à Tecnologia Assistiva. Tecnologia e Educação. Porto Alegre, RS, 2017. 


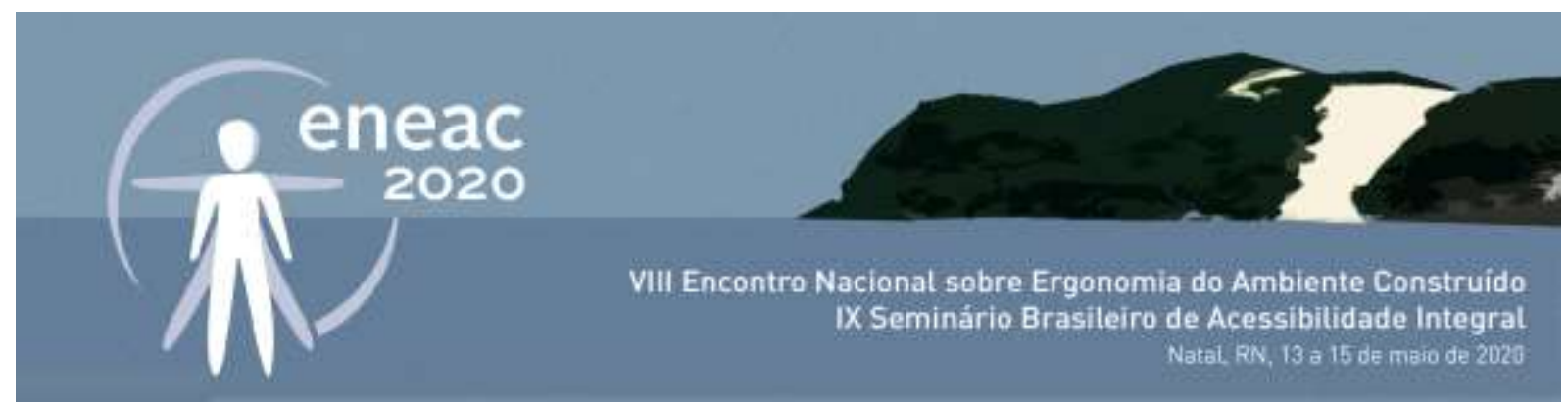

BRASIL. DECRETO N. 5.296, DE 2 DE DEZEMBRO DE 2004. Regulamenta as Leis nos 10.048, de 8 de novembro de 2000, que dá prioridade de atendimento às pessoas que especifica, e 10.098, de 19 de dezembro de 2000, que estabelece normas gerais e critérios básicos para a promoção da acessibilidade das pessoas portadoras de deficiência ou com mobilidade reduzida, e dá outras providências, Brasília, DF, dez 2004. Disponível em:

http://www.planalto.gov.br/ccivil_03/_ato2004-2006/2004/decreto/d5296.htm. Acesso em: 18 nov 2019.

CRUZ, Danielle Teles da et al. Prevalência de quedas e fatores associados em idosos. Revista Saúde Pública. 2014, vol. 46, n. 1, p. $138-146$.

ELALI, Gleice Azambuja. Avaliação pós-ocupação e responsabilidade social: Uma relação a ser sempre (re)discutida. Gestão \& Tecnologia de projetos, v. 5, n. 2, nov. 2010.

GIL, Antonio Carlos. Como elaborar projetos de pesquisa. 6. Rio de Janeiro Atlas 20171 recurso online.

JÚNIOR, Renato Campos Freire et al. Estudo da acessibilidade de idosos ao centro da cidade de Caratinga, MG. Revista Brasileira de Geriatria e Gerontologia. 2013, vol. 16, n. 3, p. 541-558.

LIMA, Deusdedit; LIMA, Maria Alice; RIBEIRO, Cristiane. Envelhecimento e qualidade de vida de idosos institucionalizados. RBCEH, Passo Fundo. 2010, vol. 7, n. 3, p. 346-356.

MINCATO, Paula Cristina; FREITAS, Cíntia de La Rocha. Qualidade de vida dos idosos residentes em instituições asilares da cidade de Caxias do Sul-RS. RBCEH, Passo Fundo. 2007, v. 4, n. 1, p. 127-138.

MORGAN, D. L. Focus groups. Annual Review of Sociology, California, v. 22, p. 129-152. 1996.

OLIVEIRA, Alysson André Régis de; FILHO, Carlos Alberto Pereira Leite, RODRIGUES, Cláudia Medianeira Cruz. $O$ Processo de Construção dos Grupos Focais na Pesquisa Qualitativa e suas Exigências Metodológicas. XXXI Encontro da ANPAD. 2007, Rio de Janeiro.

OLIVEIRA, Mirian; FREITAS, Henrique M.R. Focus Group - pesquisa qualitativa: resgatando a teoria, instrumentalizando o seu planejamento. Revista de Administração, São Paulo. V. 33, n. 3, p. 83-91, julho/setembro, 1998.

PARENT, M. et al. Knowledge creation in focus group: can group technologies help? Information \& Management. v. 28. p. 47-52, 2000.

RIBEIRO, Dâmarys et al. Fatores associados à força de preensão manual diminuída em idosos. Escola Anna Nery revista de enfermagem. 2016, vol. 20, n. 4.

SECRETARIA ESPECIAL DOS DIREITOS HUMANOS. Hotel Nacional em Brasília - DF. Ata VII Reunião do Comitê de Ajudas Técnicas - CAT CORDE / SEDH / PR Realizada nos dias 13 e 14 de dezembro de 2007. Livro (?), p. 1-4.

SILVA, V. G. Indicadores de Sustentabilidade de Edifícios: estado da arte e desafios para desenvolvimento no Brasil. Ambiente Construído, Porto Alegre, v. 7, n. 1, p. 47-66, jan./mar. 2007.

TORRES, Analucia de Lucena. O papel do ambiente residencial na qualidade de vida de idosos: Um estudo exploratório em Cabedelo, Paraíba. 2015. 205 f. Tese (Pós-graduação em Psicologia). Universidade Federal do Rio Grande do Norte, Natal.

VERGARA, Sylvia Constant. Projetos e relatórios de pesquisa em administração. 5. ed. São Paulo: Atlas, 2004. 